\title{
Ignition of HTPB-based Fuels Loaded with and without Micron-sized Metals
}

\author{
Zhao Qin ${ }^{1,2}$ \\ ${ }^{1}$ Nanjing University of Science and Technology, \\ Nanjing, China \\ ${ }^{2}$ Politecnico di Milano, \\ Milan, Italy
}

\author{
Yue Tang ${ }^{1}$, Christian Paravan ${ }^{2}$, Giovani Colombo ${ }^{2}$, \\ Ruiqi Shen ${ }^{1, *}$, Luigi T. DeLuca ${ }^{2}$ \\ ${ }^{1}$ Nanjing University of Science and Technology, \\ Nanjing, China \\ ${ }^{2}$ Politecnico di Milano, \\ Milan, Italy
}

\begin{abstract}
Hybrid propulsion is becoming more and more attractive in both military and commercial fields for its safety, low cost, and throttability. Most of the works on hybrid propulsion so far carried out is connected with the understanding of the combustion of hybrid fuels. However, the ignition of hybrid fuels, as the first step of fuel application, has received little attention. This paper discusses an experimental investigation focused on ignition phenomena of hydroxyl-terminated polybutadiene (HTPB) based fuels, using a continuous $\mathrm{CO}_{2}$ laser with a wavelength of $10.6 \mu \mathrm{m}$ as a radiation source. Gaseous oxygen was selected as oxidizer for ignition tests. Experiments were carried out at the pressure of 0.1 MPa and 1.0 MPa. Ignition delay of HTPB was found to decrease with the increasing of radiant flux, and the relationship between ignition delay $\left(t_{i}\right)$ and incident radiant flux $(q)$ can be described as $t_{i}=a q^{n}$, with $n=-1.16$ at $0.1 \mathrm{MPa}$ and $n=-1.00$ at $1 \mathrm{MPa}$. Ignition delay of HTPB based fuels did have a dependence on pressure. Mg, $\mathrm{MgB}$, and am_ Al powers are demonstrated to have a positive effect on decreasing ignition delay of HTPB fuels.
\end{abstract}

Keywords-ignition delay; НТРВ fuel; laser irradiation; metal additives; pressure

\section{INTRODUCTION}

Hybrid propulsion systems have many advantages over conventional solid- and liquid-propulsion systems, such as low-cost, safety, throttability, making them more and more attractive for both military and commercial applications [1, 2]. Numerous works about hydroxylterminated polybutadiene (HTPB) fuels have already been carried out cover the main field on increasing regression rate $[1,3-6]$. However, ignition of hybrid fuels, as the first step of fuel application, has received little attention. Pioneering studies on solid fuel ignition were performed by
Ohlemiller and Summerfield [7], who conducted radiative ignition test on polystyrene and an epoxy in oxygen/nitrogen as early as 1971. Effects of radiant flux, pressure, oxygen percentage, and fuel absorption coefficient on ignition delay were discussed. In 1973, a radiative ignition model of a solid fuel including the gas phase reaction and the in-depth absorption of the incident radiation by its solid phase was proposed by Kashiwagi; however, the pressure effect was not considered [8]. In order to accelerate the development of hybrid propulsion, it is necessary to investigate the ignition phenomena of these fuels.

Ignition test of solid fuel under $\mathrm{CO}_{2}$ irradiation was carried out with gaseous oxygen flow at $0.1 \mathrm{MPa}$ and 1.0 $\mathrm{MPa}$. Experiments were implemented to check pressure effects on the ignition delay, while ignition characteristic of solid fuel under different radiant flux was investigated at the same time. Innovative micron sized metal powers such as $\mathrm{MgB}$ and amorphous aluminum (am_Al) were selected to check its effect on ignition delay of HTPB based fuels.

\section{EXPERIMENTAL DETAILS}

\section{A. Fuel Formulation}

Detailed formulation on HTPB fuel used in this investigation is presented in Table I. Isophorone diisocyanate (IPDI) is used as curing agent, while dibutyltin diacetate (TIN) is used as curing catalyst in order to avoid possible subsidence. Curing level $(-\mathrm{NCO} /-\mathrm{OH})$ is 1.04 for all the formulations. Manufacture is carried out in vacuum with a mechanical mixer.

TABLE I: HTPB FUEL FORMULATION AND INGREDIENTS DENSITY.

\begin{tabular}{|c|c|c|c|}
\hline Ingredients & $\begin{array}{c}\text { Mass } \\
\text { Fraction, } \\
\%\end{array}$ & $\begin{array}{c}\text { Density, } \\
\rho, \mathrm{kg} / \mathrm{m}^{3}\end{array}$ & Supplier \\
\hline $\begin{array}{c}\text { Hydroxyl-Terminated Polybuta- } \\
\text { diene (HTPB R45) }\end{array}$ & 78.86 & 901 & Sartomer \\
\hline Dioctyl Adipate (DOA) & 13.04 & 920 & ACROS/Carlo Erba \\
\hline Isophorone diisocyanate (IPDI) & 7.67 & 1060 & $\begin{array}{c}\text { Alfa Aesar GmbH \& Co. } \\
\text { KG }\end{array}$ \\
\hline Dibutyltin diacetate (TIN) & 0.43 & 1310 & ACROS/Carlo Erba \\
\hline HTPB binder & 100 & 920 & \\
\hline
\end{tabular}


Two innovative micron sized metal powders (MgB and am_Al) and one traditional metal particle $(\mathrm{Mg})$ were selected to be added into HTPB binder in order to check their effect on ignition delay under laser irradiation. Average diameter of $\mathrm{MgB}$ and am_Al is $5.17 \mu \mathrm{m}$ and $83.67 \mu \mathrm{m}$, respectively, while diameter of $\mathrm{Mg}$ is less than $47 \mu \mathrm{m}$. Mass fraction of metal additives is presented in
Table II, while the remaining mass fraction is HTPB binder. Although mass fraction of additives in each fuel is different, the molar content of main metal (Mg, B, and $\mathrm{Al}$ ) was maintained to $0.37 \mathrm{~mol} / 100 \mathrm{~g}$ in each fuel. Samples for tests were cut into 8-mm-diam, 5-mm-high cylinders. The surface to be irradiated was carefully cleaned by acetone before the ignition tests.

TABLE II: COMPOSITION AND DENSITY OF TESTED FUELS.

\begin{tabular}{|c|c|c|c|c|}
\hline No. & $\begin{array}{c}\text { Additives } \\
\text { (by wt\%) }\end{array}$ & $\begin{array}{c}\text { Theoretical } \\
\text { Density, } \rho_{\text {TMD }}, \\
\mathrm{kg} / \mathrm{m}^{3}\end{array}$ & $\begin{array}{c}\text { Measured Density, } \\
\rho_{\mathrm{MD}}, \mathrm{kg} / \mathrm{m}^{3}\end{array}$ & Porosity, \% \\
\hline 1 & None & 915 & $922 \pm 1.9$ & $0.8 \pm 0.2$ \\
\hline 2 & $8.9 \% \mathrm{Mg}$ & 956 & $957 \pm 1.8$ & $0.1 \pm 0.2$ \\
\hline 3 & $2.8 \% \mathrm{MgB}^{\mathrm{a}}$ & 930 & $935 \pm 1.1$ & $0.5 \pm 0.1$ \\
\hline 4 & $14.2 \% \mathrm{am}_{-} \mathrm{Al}^{\mathrm{b}}$ & 1018 & $1022 \pm 0.5$ & $0.4 \pm 0.1$ \\
\hline
\end{tabular}

${ }^{\mathrm{a}} \mathrm{MgB}$ is a dual metal composed by magnesium (Mg) and boron (B). MgB used in this study is composed by $20 \% \mathrm{Mg}$ and $80 \% \mathrm{~B}$ with $90 \%$ purity bam_Al is an alloy of aluminum (Al), iron ( $\mathrm{Fe}$ ) and yttrium (Y), with mass fraction of $70.30 \%, 13.54 \%$, and $16.16 \%$ respectively.

\section{B. Experimental Setup}

All of the tests were conducted in a stainless cylinder chamber. A scheme of the implemented setup is presented in Figure 1. Gaseous oxygen was selected as oxidizer. Mass flow of oxygen was injected into the chamber, adjusted to 5 LPM during all of the ignition tests, and it was controlled by a mass flow meter. A continuous $\mathrm{CO}_{2}$ laser emits a beam with a wavelength of $10.6 \mu \mathrm{m}$ and spot diameter of $1.5 \mathrm{~cm}$. However, only $4 \mathrm{~mm}$ in the center of the beam, which is nearly uniform, was used to ignite the fuel. The power of the laser could be varied from 0 to 180 $\mathrm{W}$ by adjusting the current through the laser discharge tube. The radiation flux was measured with a dedicated setup for $\mathrm{CO}_{2}$ laser. Two optical sensors were used in the experiment, one for the signal of laser and the other one for the ignition of fuel. A high speed camera was used to record ignition progress.

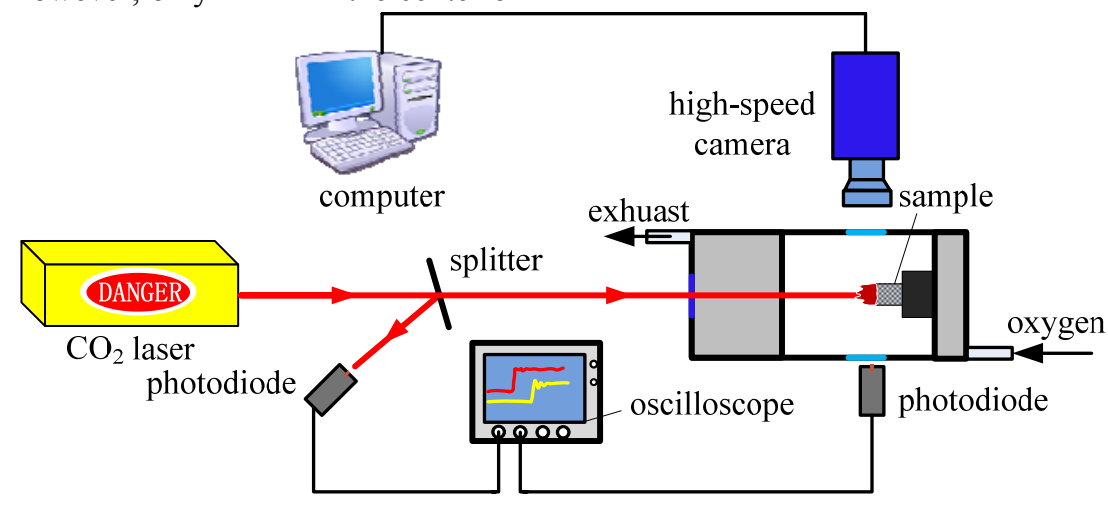

Figure 1. Scheme of experiment setup.

\section{RESULTS AND DISCUSSION}

Ignition tests were carried out at $0.1 \mathrm{MPa}$ and $1.0 \mathrm{MPa}$ with laser flux density in the range of $50-200 \mathrm{~W} / \mathrm{cm}^{2}$. More than three tests were performed for each condition in order to reduce possible errors.

A typical result of an ignition test is shown in Figure 2. Beam emitted from the laser becomes stable in about $5 \mathrm{~ms}$, illustrating that it could be used for ignition test of hybrid fuels. Time between the start of stable laser and the first flame of the fuel was regarded as ignition delay. Signal for the flame of the fuel after the ignition is nearly a straight line, suggesting that fuel firmly burned as soon as it was ignited. 


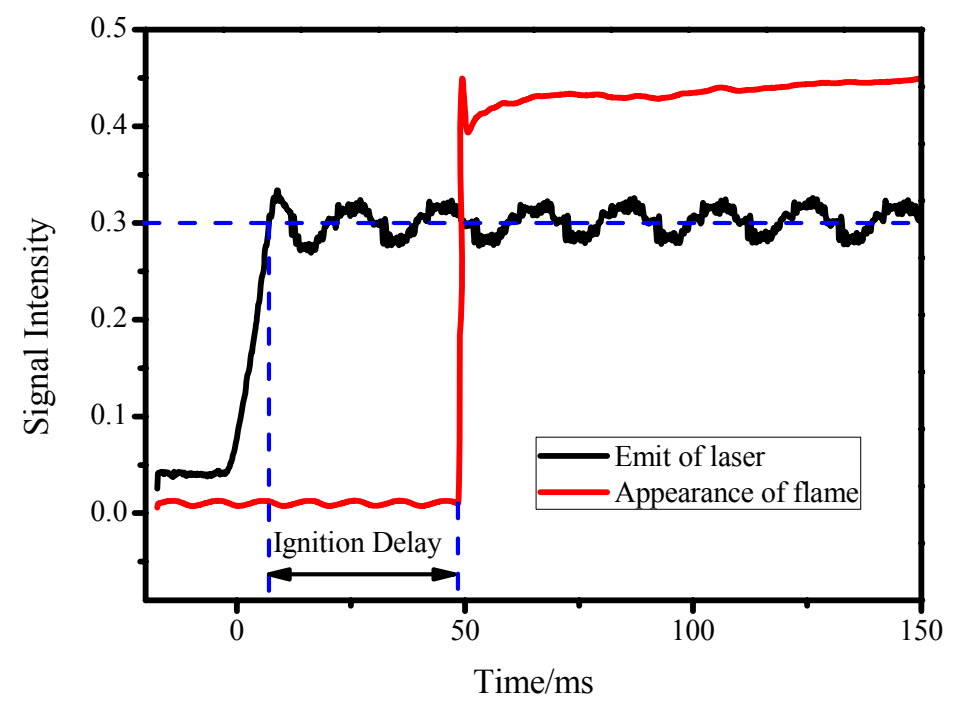

Figure 2. Typical result of ignition test.

\section{A. Pressure Effect}

Ignition delay of fuels at $0.1 \mathrm{MPa}$ and $1.0 \mathrm{MPa}$ is presented in Figure 3. In general, ignition delay was decreased greatly when the ambient pressure was increased from $0.1 \mathrm{MPa}$ to 1.0 $\mathrm{MPa}$ over the whole range of radiant flux investigated in this study. With laser radiant flux of $56 \mathrm{~W} / \mathrm{cm}^{2}$, ignition delay at $1.0 \mathrm{MPa}$ was decreased to $54 \%$ of the one at $0.1 \mathrm{MPa}$. However, when laser radiant flux comes to $134 \mathrm{~W} / \mathrm{cm}^{2}$, ignition delay at $1.0 \mathrm{MPa}$ is about $69 \%$ of that at $0.1 \mathrm{MPa}$.

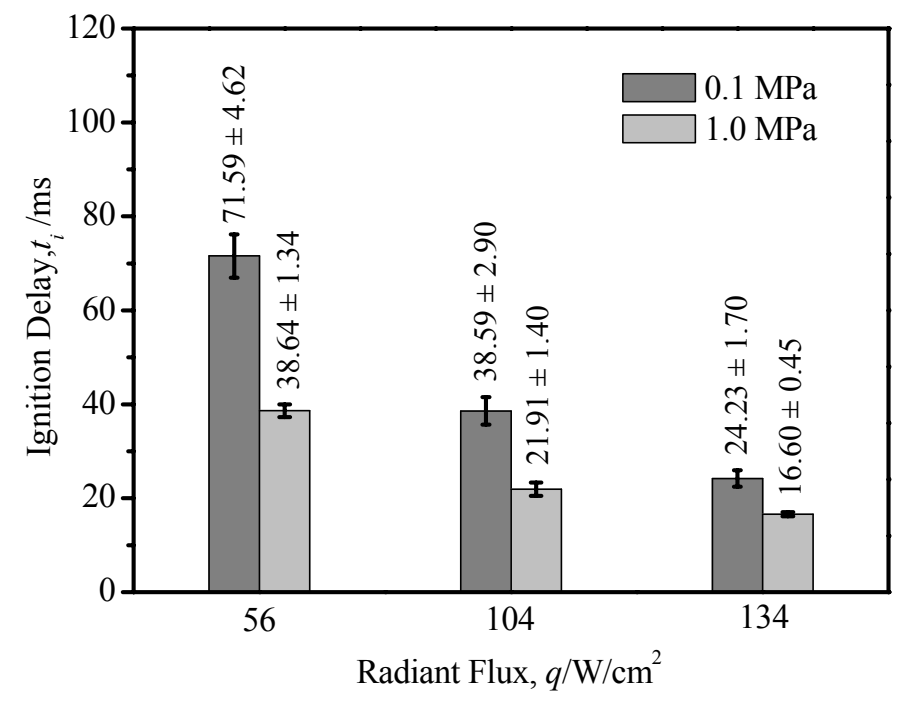

Figure 3. Ignition delay of HTPB with oxygen flow under laser irradiation; 0.1 MPa and 1.0 MPa; 5LPM.

Pressure dependence under higher radiant flux was impaired since irradiation is too strong. Laser was so strong that pressure dependence of ignition delay was decreased. High pressure dependence of HTPB fuel's ignition delay is consistent with the results of epoxy under $\mathrm{CO}_{2}$ laser irradiation, conducted by Ohlemiller and Summerfield in 1971 [7].
Since the distance between reaction zone and solid phase was decreased with the increasing of pressure, this could be one reason for the pressure dependence. Higher concentration of gaseous fuel on condensed surface of HTPB fuel at higher pressure, as soon as the fuel was irradiated, could be another important reason for this diffusion ignition progress. 
Healy et al. [9] reported that the ignition temperature of $n \mathrm{C}_{4} \mathrm{H}_{10}$ decreased with the increasing of ambient pressure. If this is true to hybrid fuel too, lower ignition temperature at higher pressure should be main reason for high pressure dependence of ignition delay.

\section{B. Laser radiant Flux Effect}

In Figure 4, ignition delay of solid fuels under different laser irradiation in oxygen is presented. Ignition delay of all of the fuels decreased with the increasing of radiant flux. Relationship between ignition delay $\left(t_{i}\right)$ and radiant flux $(q)$ can be described by Eq. (1), which coincides with classic theory of solid propellant under laser irradiation [10].

$$
t_{i}=A q^{-n}
$$

where $A$ and $n<2$ are constants. $A$ and $n$ of all the fuels tested are listed in Table III. As can be seen from Table 3, all of the index number $n$ is very close to 1.0; however, the factor $A$ for each fuel is quite different.

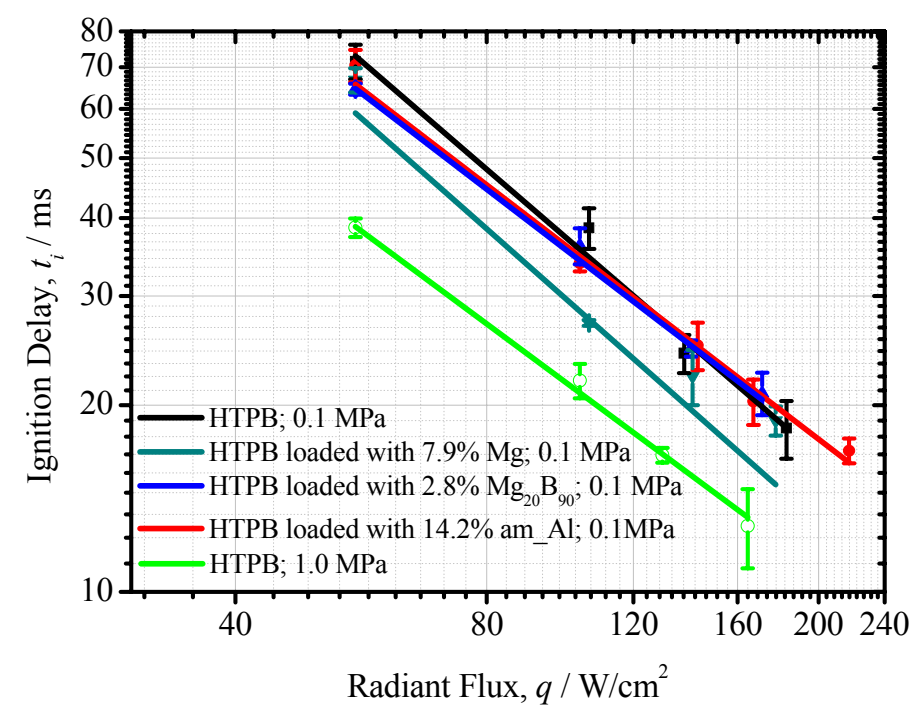

Figure 4. Ignition delay of solid fuels in oxygen under CO2 laser irradiation; O2, 5 LPM.

Table III. Solid Fuels Ignition in Oxygen under Laser Irradiation, Relationship between Ignition Delay vs Radiant Flux.

\begin{tabular}{|c|c|c|c|c|}
\hline Fuel & $\begin{array}{c}\text { Pressure, } \\
\mathrm{MPa}\end{array}$ & $A$ & $n$ & $\begin{array}{c}R^{2}, \text { Eq. } \\
(1)\end{array}$ \\
\hline \multirow{2}{*}{ HTPB } & 0.1 & $7702.7 \pm 3387.8$ & $1.159 \pm 0.095$ & 0.971 \\
\cline { 2 - 5 } & 1.0 & $2130.48 \pm 265.17$ & $0.997 \pm 0.027$ & 0.997 \\
\hline HTPB loaded with Mg & 0.1 & $7045.15 \pm 7738.19$ & $1.189 \pm 0.236$ & 0.847 \\
\hline HTPB loaded with MgB & 0.1 & $4038.45 \pm 419.79$ & $1.029 \pm 0.024$ & 0.998 \\
\hline $\begin{array}{c}\text { HTPB loaded } \\
\text { with am_Al }\end{array}$ & 0.1 & $4123.19 \pm 1104.67$ & $1.134 \pm 0.047$ & 0.993 \\
\hline
\end{tabular}

In general, metal additives have positive effect on decreasing ignition delay of HTPB fuels; nevertheless, ignition delay were not shortened greatly with the help of metal additives (less than 30\%) indicating that $\mathrm{Mg}$, $\mathrm{MgB}$, and am_Al are insensitive to $\mathrm{CO}_{2}$ laser irradiation, and the absorption effect of these metal particles at 10.6 $\mu \mathrm{m}$ laser irradiation is less than that of carbon black used in solid propellant $[7,11,12]$. Magnesium, as a conventional metal additive, shows a better effect on decreasing ignition delay with respect to any other additive.

\section{CONCLUSION}

Ignition tests of HTPB based solid fuel were conducted in oxygen at both $0.1 \mathrm{MPa}$ and $1.0 \mathrm{MPa}$ under $\mathrm{CO}_{2}$ laser irradiation. Ignition delay of HTPB based fuel was found to decrease as the increasing of radiant flux, and the relationship between ignition delay $\left(t_{\mathrm{i}}\right)$ and the incident radiant flux $(q)$ can be described by $t_{i}=\mathrm{A} q^{n}$, with $n=-1.16$ at $0.1 \mathrm{MPa}$ and $n=-1.00$ at $1 \mathrm{MPa}$. Ignition delay of solid fuel was decreased to $54 \%$ when pressure was increased from $0.1 \mathrm{MPa}$ to $1.0 \mathrm{MPa}$ with radiant flux of 56 $\mathrm{W} / \mathrm{m}^{2}$. However pressure effect on ignition delay was impaired as the increasing of laser radiant flux. Compared to $\mathrm{MgB}$ and am_Al, traditional micron sized $\mathrm{Mg}$ powers are demonstrated to have a better effect on decreasing ignition delay of HTPB fuels. 


\section{ACKNOWLEDGMENTS}

The authors would like to thank MACH I, USA, for providing $\mathrm{MgB}$ samples.

\section{REFERENCES}

1] M.J. Chiaverini, et al, Regression-rate and heat-transfer correlations for hybrid rocket combustion. Journal of Propulsion and Power, 17(1), pp. 99-110, 2001

[2] L. DeLuca, et al., Time-resolved burning of solid fuels for hybrid rocket propulsion. Progress in Propulsion Physics. EDP Sciences, 2011.

[3] D. Pastrone, Review Approaches to low fuel regression rate in hybrid rocket engines. International Journal of Aerospace Engineering, pp. 1-12, 2012.

[4] G. Risha, et al, Performance comparison of HTPB-based solid fuels containing nano-sized energetic powder in a cylindrical hybrid rocket motor. In 38th AIAA/ASME/SAE/ASEE Joint Propulsion Conference and Exhibit, Indianapolis, IN, 2002.

[5] G. Risha, et al., Metals, energetic additives, and special binders used in solid fuels for hybrid rockets. Progress in Astronautics and Aeronautics, 218, p. 413, 2007.
[6] G.A. Risha, et al., Combustion of HTPB-based solid fuels containing nano-sized energetic powder in a hybrid rocket motor. AIAA Paper, 3535, 2001.

[7] T.J. Ohlemiller, M. Summerfield, Radiative ignition of polymeric materials in oxygen nitrogen mixtures. In 13th Symposium (International) on Combustion. Combustion Institute, Pittsburg. p. 10871094, 1971.

[8] T. Kashiwagi, A radiative ignition model of a solid fuel. Combustion Science and Technology, 8(5-6), pp. 225-236, 1973.

[9] D. Healy, et al., n-Butane: Ignition delay measurements at high pressure and detailed chemical kinetic simulations. Combustion and Flame, 157(8), pp. 1526-1539, 2010.

[10] B.N. Kondrikov, L.T. DeLuca, Delayed ignition of solid propellants under thermal radiation. AIAA Journal, 2001.

[11] L.T. DeLuca, L.H. Caveny, T.J. Ohlemiller, Radiative ignition of double-base propellants: I. Some formulation effects. AIAA Journal, 14(7), pp. 940-946, 1976.

[12] L.T. DeLuca, T.J. Ohlemiller, M. Summerfields, Radiative ignition of double base propellants: II. Pre-ignition events and source effects. AIAA Journal, 14(8), pp. 1111-1117, 1976. 